\title{
SMART BATTERY CHARGER FOR ELECTRIC MOBILITY IN SMART GRIDS
}

\author{
Vítor Monteiro ${ }^{1}$, João C. Ferreira ${ }^{2}$ and João L. Afonso ${ }^{3}$ \\ ${ }^{1,3}$ Centro Algoritmi, Univ. of Minho, Guimarães, Portugal \\ ${ }^{2}$ ADEETC, ISEL, Lisboa, Portugal \\ $\left\{\right.$ vmonteiro, jla\}@dei.uminho.pt ${ }^{1,3}$,and jferreira@deetc.isel.ipl.pt $t^{2}$
}

Keywords: SMART GRIDS, ELECTRIC VEHICLES, SMART BATTERIES CHARGING, VEHICLE-TO-GRID, GRID-TO-VEHICLE, ELECTRIC MOBILITY, POWER QUALITY.

\begin{abstract}
In this paper is presented the development of a smart batteries charger for Electric Vehicles (EVs) and Plug-in Hybrid Electric Vehicles (PHEVs), aiming their integration in Smart Grids. The batteries charging process is controlled by an appropriate control algorithm, aiming to preserve the batteries lifespan. The main features of the equipment are the mitigation of the power quality degradation and the bidirectional operation, as Grid-to-Vehicle (G2V) and as Vehicle-to-Grid (V2G). During the charging process (G2V), the consumed current is sinusoidal and the power factor is unitary. Along the discharging process (V2G), when the equipment allows delivering back to the electrical power grid a small amount of the energy stored in the batteries, the current is also sinusoidal. The V2G mode of operation will be one of the main features of the Smart Grids, both to collaborate with the electrical power grid to increase stability, and to function as a distributed Energy Storage System (ESS). The functioning of the smart batteries charger is shown through simulation and experimental results, both during the charging $(\mathrm{G} 2 \mathrm{~V})$ and the discharging $(\mathrm{V} 2 \mathrm{G})$ modes of operation. Also in this paper are shown and briefly described the roles of the key concepts related with the Smart Grids in terms of Systems and Functional Areas, Power Electronics Systems, and Electric Mobility.
\end{abstract}

\section{INTRODUCTION}

The upcoming reality of smart grids and electrical power markets will raise a diversity of advantages to the end-user, because he isn't longer a passive client. However, it will require several developments and studies aiming the integration of smart grid, users, electricity markets and others. The Electric Vehicles (EVs) and the Plug-In Hybrid Electric Vehicles (PHEVs) are seen as one of the most promising means in order to improve the sustainability of the transportation and energy sectors in near-term (Bradley, 2009).

In an overview, the smart grid is a conjunction of technologies that allows the application of the Information and Communication Technology (ICT) to the electrical power grid, allowing predict the energy demand and control the production. It consists in transform the electrical power grid through information technology using advanced communication techniques and control algorithms, transforming the grid on a coordinated, collaborative, and automatic infra-structure (Sekyung et al., 2010), (Ferreira et al., 2011). The European Technology Platform Smart Grids (ETPSG) defines the Smart Grid as "an electricity network that can intelligently integrate the actions of all users connected to it - generators, consumers and those that do both, in order to efficiently deliver sustainable, economic and secure electricity supply" (ETPSG, 2010).

Specifically, the Smart Grid involves the installation of different devices, tools and technologies in the electric power grid in order to establish a bidirectional flux of information's about the operation and performance of the grid, from the generation to the transmission and distribution grid, improving in this way, the reliability, the security against to physical and cyber-attacks and major natural phenomena (e.g. hurricanes, earthquakes, and tsunamis), and the efficiency.

In a Smart Grid, one of the main features is the efficiency, which to the concessionary companies 
implies less energy losses to have the same level of the service quality provided to the clients. Increasing the efficiency, it is also possible reduce the costs and reduce the emission of greenhouse gases. With a great amount of information about the generation and distribution system and the customers habits it is possible define operation strategies and control algorithms to the electrical power grid in order to control the system demands and costs, while increasing energy efficiency and assuring an optimal power quality for all clients.

Aiming the reliability in the electrical power grid, with the constant monitoring of the grid, it is possible detects and identifies when the Smart Grids equipment's are starting to fail or the performance is in decline, and with this allows correct the problems avoiding damages to the electrical power grid and to the clients. In a Smart Grid scenario it will also be possible detect a failure and locate it with precision, allowing repair the problem fast or isolating the impact of the problem protecting the maximum number of clients possible.

Through a smart control and smart meters in Smart Grids, will allow the integration in large scale of renewables reducing the environmental impact of production, and the integration of EVs and PHEVs (Clement, 2009), that can interact with the electrical power grid as isolated loads or as Energy Storage Systems (ESS). Nowadays, with the increase bet in $\mathrm{EV}$ and PHEV, the actual electrical power grid is facing new challenges, forcing to a wide efforts of investigation in different directions aiming the electric mobility. In this context, the electric power industry is also facing a challenge motivated by the need to adopt policies to reducing the impacts of global climate change, and the need for energy security reached with the reduction of imbalances between the supply and demand. Thereby, aiming this challenge, in this paper is presented a smart batteries charger, that can be implemented in EVs or PHEVs, and that allows mitigate problems associated with power quality (as distorted current consumption and low power factor), contributing to the efficiency and reliability of the electric mobility in Smart Grids. This smart batteries charger, unlike typical chargers, consumes sinusoidal current with unitary power factor, and allows bidirectional functioning as Vehicle-to-Grid (V2G).

\section{SMART GRIDS}

In Figure 1 are shown three technological areas associated to Smart Grids: Systems and Functional

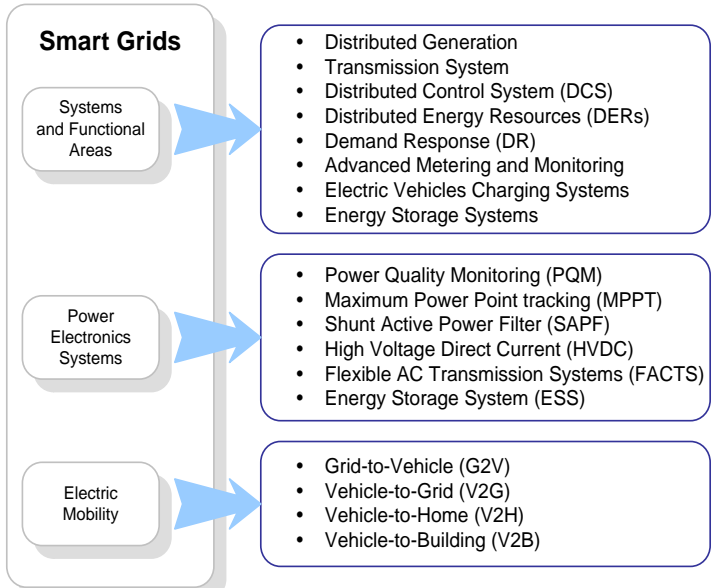

Figure 1: Smart Grids: Systems and Functional areas; Power Electronics Systems; and Electric Mobility.

Areas (Carvalho, 2011); Power Electronics Systems (Bollen et al., 2010); and Electric Mobility.

\subsection{Systems and Functional Areas}

In a Smart Grid context with the increasing of the energy efficiency in the production, in the transmission and distribution system, as well as in the consumption, results in a significant reduction of energy consumption. To achieve this goal several systems and functional areas in Smart Grids should be taken into account.

\subsection{Power Electronics Systems}

The currently electrical power grid consists in the conventional sources of energy and some sources of renewables. However, in a Smart Grid context, this scenario will be integrated with thousands sources of renewables through the microgeneration, allowing reduce the use of the energy transmission and distribution system and the losses associated. It will be also capable of autonomous operation with communication with the grid or as an isolated grid. To integrate the microgeneration in a Smart Grid context it is necessary the use of equipment's based on power electronics, in order to converter the energy from the renewables into energy to be delivered to the electrical power grid.

With the advancements in the field of power electronics, combined with proper control algorithms to the integration on the electrical power grid, there are a large variety of operations and options to the Smart Grid, aiming an efficient management. In Figure 2 is shown an application example of power electronics in Smart Grids, 


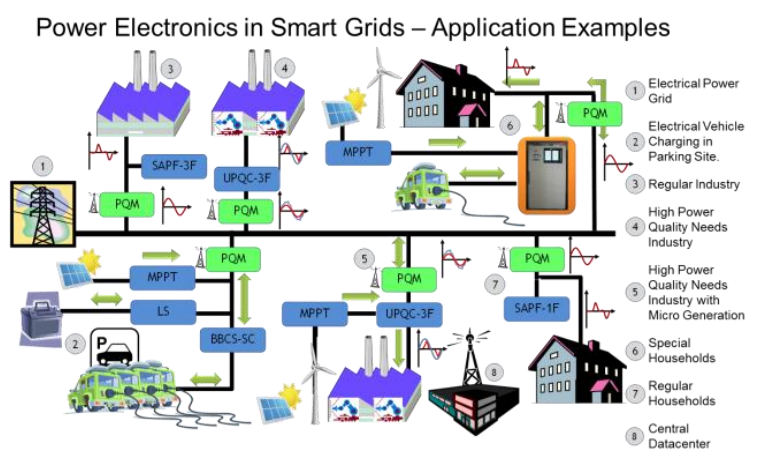

Figure 2: Power Electronics in Smart Grids.

considering typical houses with or without EV and renewables, typical industries, industries with interface to renewables, parking to EV charging with interface with renewables and ESS, and the a data center to collect the data from the monitors in each point of consumption. The power flux with the electrical power grid can be unidirectional or bidirectional. Then are defined some of the most important low power equipment's associated with power electronics in Smart Grids.

\subsection{Electric Mobility}

The EV smart charging technology, essentially, will allow the communication of EVs with local utilities to ensure that the batteries are charged when the electricity is cheapest and the impact on the grid is smallest. The use of computerized charging stations which constantly monitor the EV charging process to optimize the charging rate it will be extremely important to preserve the batteries lifespan.

The concept Grid-to-Vehicle (G2V) is the simplest process to integrate the EV and PHEV in the electrical power grid. It is not absolutely required communication between both and only exist flow of energy from the electrical power grid to the vehicles. Nowadays, this is the most common procedure to charge the batteries of EV and PHEV, and it will be the first approach to the massive integration of these vehicles.

The concept V2G consists in the bidirectional flux of energy between EV and PHEV and the electrical power grid. With the massive adoption of $\mathrm{EV}$ and PHEV, the batteries charging process needs assistance of an intelligent process in order to find the periods with cheaper prices to charge batteries, to identify the available charging slots (in public areas), and to provide other useful information to the drivers, as their historic use. The Mid-Atlantic Grid Interactive Cars Consortium (MAGICC) defines
V2G as a technology that utilizes the stored energy in the EV batteries to contribute with electricity back to the grid when the grid operators request it (MAGICC, 2011). This technology makes an interaction between vehicles and grid, in order to control the needs of both.

The concept Vehicle-to-Home (V2H) is similar to the V2G concept; however it can avoid the grid infrastructure and the electricity tariff problems associated with $\mathrm{V} 2 \mathrm{G}$, because the bidirectional flux of energy is between the vehicle and the house. Thereby, $\mathrm{V} 2 \mathrm{H}$ can be used to manage and regulate the profile of electricity demand in the house, controlling the use of the loads and the stored energy available in the vehicle.

A specific version of $\mathrm{V} 2 \mathrm{G}$, denominated Vehicleto-Building (V2B), is a concept that consists in use the stored energy in the batteries of EV and PHEV as an energy source of back-up to compensate the energy consumption profile in commercial scale (e.g. when the vehicle is parked to the driver go work or go shopping).

\section{PROPOSED SMART CHARGER}

EVs and PHEVs are becoming a part of the electric power grid day by day, and consequently, the chargers for these vehicles have the ability to make this interaction better for the consumer and for the grid. A battery charger is a device that is composed of one or more power electronics circuits used to convert the AC electrical energy into DC with an appropriate voltage level so as to charge a battery. It has the potential to increase charging availability of the EVs and PHEVs since it can operate as universal converter accepting different voltage and power levels. An advanced charger performs several functions in addition to the charging operation for better grid integration, mainly taking into account the power quality. Independently the level of the charging, to the integration of the EVs and PHEVs in a Smart Grid context aiming the power quality, the chargers should consume sinusoidal current with unitary power factor.

To single-phase converters, the most common converter with a sinusoidal current consumption and unitary power factor is implemented with the boost converter with proper control algorithms. In (Wei, 1998) are compared the basic converter topologies for Power Factor Correction (PFC) (buck, boost, buck-boost, flyback, forward, cuk, sepic, and zeta). On other hand, there are also three-phase solutions with PFC capability. 


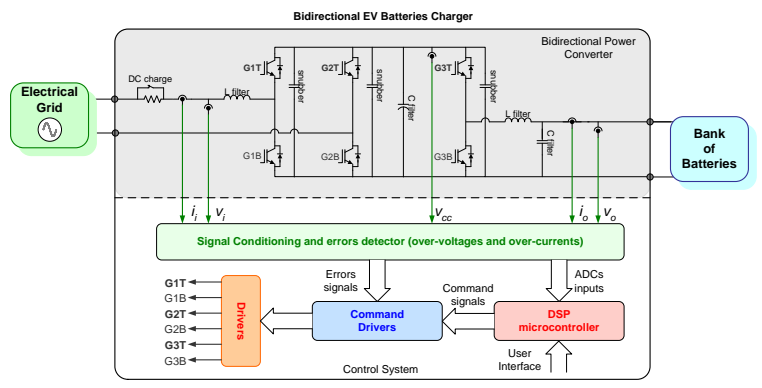

Figure 3: Schematic of the developed batteries charger.

Focusing the EVs and PHEVs converters with a bidirectional mode of operation, in (Wiedemuth et al., 2007) are presented single-phase bidirectional AC-DC converters for PHEVs applications, and in (Kisacikoglu, 2010) is made an examination of a PHEV bidirectional charger (on-board) system for $\mathrm{V} 2 \mathrm{G}$ reactive power compensation, however, this compensation only have interest for particular cases, because the main goal of the $\mathrm{V} 2 \mathrm{G}$ is delivering to the electrical power grid active power.

The bidirectional power converter proposed to charge the batteries is composed by two power electronics converters, one AC-DC and other DC-DC. In Figure 3 is presented the schematic of the EV batteries charger developed. This charger consumes sinusoidal current with unitary power factor, has fewer components when compared to more complex topologies, and allow the bidirectional functioning.

The control system has as main function implement the control algorithms. For this purpose, the input current, the voltage in the DC bus, and the voltage and current in output are the main variables to be controlled by the control algorithm. The system control receive these signals from the conditioning circuit (used to adjust the voltage levels of the signals), and through the microcontroller (Texas Instruments DSP), are processed the control signals to the command circuit (which as a function adapt the microcontroller signals to the IGBTs drivers and control the signal of the errors detector circuit), and then are generated the pulses to the IGBTs.

\section{SIMULATIONS RESULTS}

In order to analyse the behaviour of the proposed converter was made different simulations using the simulation tool PSIM. For all simulations was used an electric model of the AGM (Absorbed Glass Mat) batteries with nominal voltage $204 \mathrm{~V}$ and nominal capacity $33 \mathrm{Ah}$, making a $6.7 \mathrm{kWh}$ bank of batteries.

The results obtained in simulation during the charging process are shown in Figure 4. As shown, the consumed current is sinusoidal and in phase with the voltage.

The results obtained in simulation during the discharging process are shown in Figure 5. As shown the current is sinusoidal and in phase opposition with the voltage.

\section{EXPERIMENTAL RESULTS}

The principle of functioning of the proposed bidirectional batteries charger was demonstrated in simulations in the previous item. Thus, in this item, is presented the developed prototype and is described its hardware, mainly the bidirectional power converter and its control system, and are shown experimental results of the developed prototype obtained with the oscilloscope Yokogawa DL708E. These results were obtained with AGM (Absorbed Glass Mat) batteries with nominal voltage $204 \mathrm{~V}$ and nominal capacity $33 \mathrm{Ah}$, making a $6.7 \mathrm{kWh}$ bank of batteries, which are in a prototype of an EV.

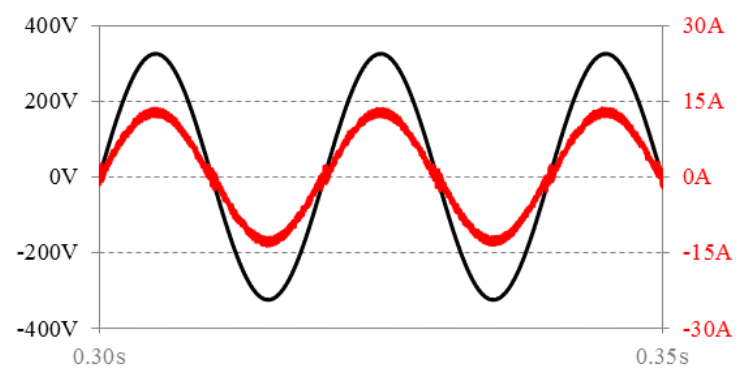

Figure 4: Simulation results: voltage and current in the electrical power grid during the charging process $(\mathrm{G} 2 \mathrm{~V})$.

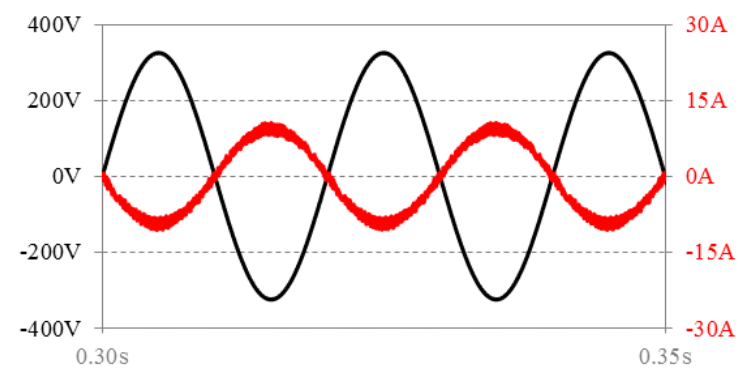

Figure 5: Simulation results: voltage and current in the electrical power grid during the discharging process (V2G). 


\subsection{Developed Prototype}

A prototype of the bidirectional batteries charger was developed in laboratory. It consists in two bidirectional power converters, one AC-DC and other DC-DC. The bidirectional power converter is composed by IGBTs modules (two modules to the AC-DC converter and the other one to the DC-DC converter). The IGBTs drivers, the snubber capacitors, the heatsink, and the current and voltage filters, are also part of the bidirectional power converters. The control system is composed by the DSP TMS320F28335, the command circuit which receive the signals from the microcontroller and through a control logic combined with the errors signals process the signals to the IGBTs drivers, and the signal conditioning circuit to adjust the signals from the sensors and to detects errors.

In Figure 6 is shown the prototype of the bidirectional batteries charger that was developed in laboratory. Currently, this prototype is under test at an EV. To charge the batteries, was used the algorithm presented in the flowchart of the Figure 7 and which consist in 3 distinct stages of voltage and current. As shown in Figure 8, in steady state, the consumed current $\left(i_{i}\right)$ is sinusoidal and in phase with the voltage $\left(v_{i}\right)$. As intended the output voltage $\left(v_{o}\right)$ is constant. To discharge the batteries, in order to preserve their lifespan, they were only discharged until $20 \%$ of their SoC, which correspond to an $80 \%$ of Depth of Discharge (DoD). In Figure 9 is shown the obtained results to the electrical power grid voltage $\left(v_{i}\right)$, to the consumed current $\left(i_{i}\right)$, and to the discharging voltage of the batteries $\left(v_{o}\right)$, during a short period, when part of the stored energy in the batteries is delivered back to the electrical power grid. As shown in figure the injected current is sinusoidal and in phase opposition with the electrical power grid voltage

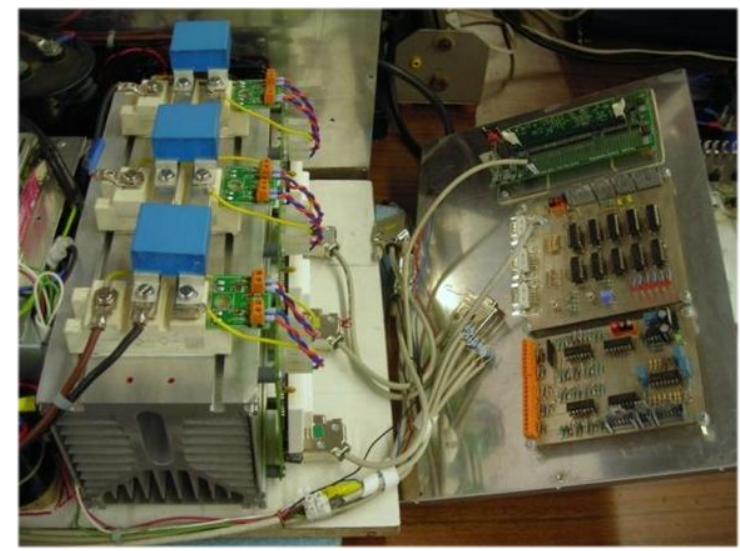

Figure 6: Developed prototype of the smart bidirectional batteries charger.

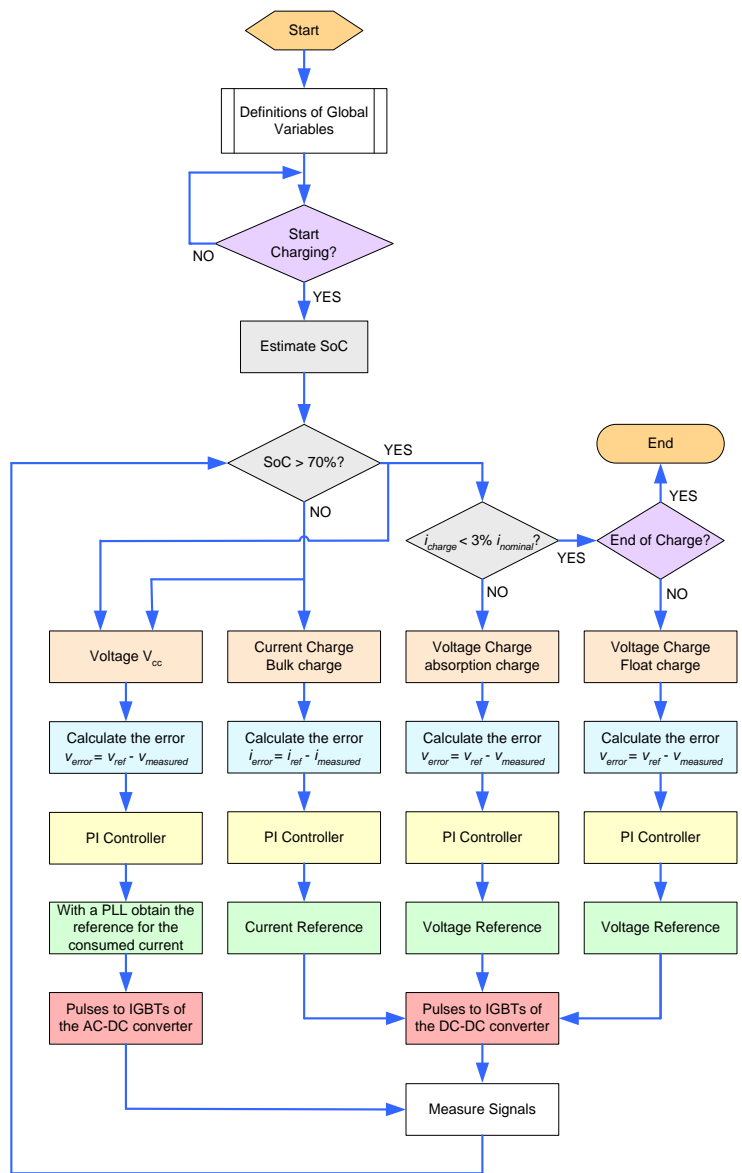

Figure 7: Flowchart of the algorithm (with 3 distinct stages of voltage and current) used to charge the batteries.

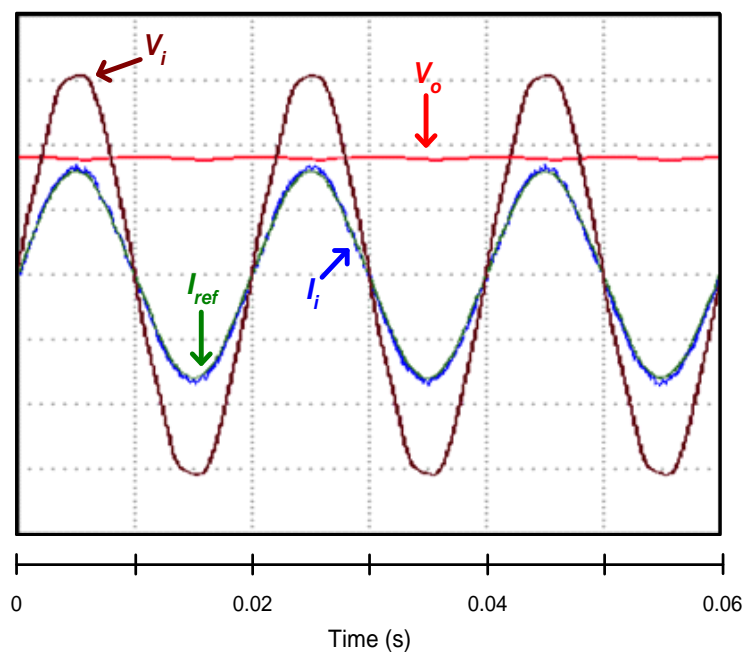

Figure 8: Experimental results: batteries charging process $(\mathrm{G} 2 \mathrm{~V})$ : electrical power grid voltage $\left(v_{i}\right)$, consumed current $\left(i_{i}\right)$, and charging voltage at the batteries $\left(v_{o}\right)$. 


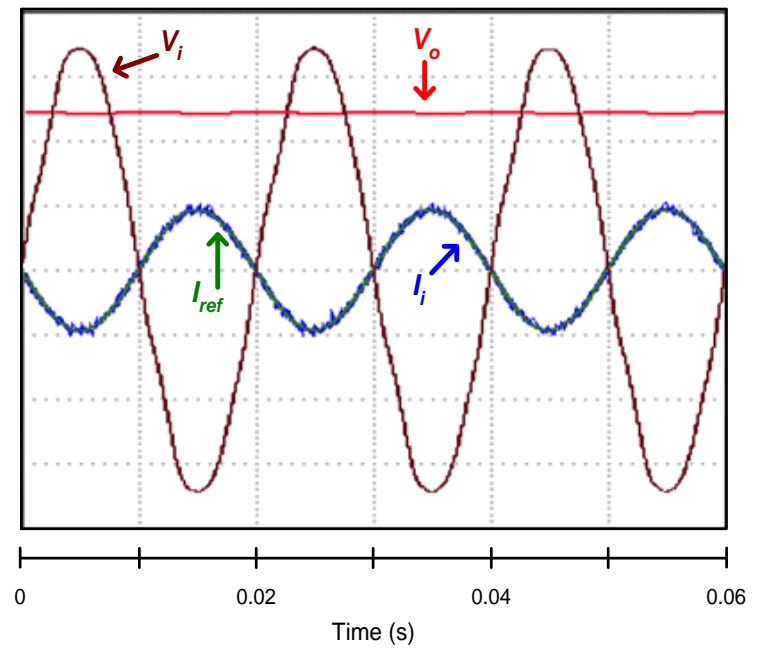

Figure 9: Experimental results: batteries discharging process: electrical power grid voltage $\left(v_{i}\right)$, consumed current $\left(i_{i}\right)$, and discharging voltage at the batteries $\left(v_{o}\right)$.

\section{CONCLUSIONS}

In this paper was presented a smart batteries charger for Electric Mobility, which can be used with Electric Vehicles (EVs) and Plug-in Hybrid Electric Vehicles (PHEVs), aiming their integration in Smart Grids, allowing mitigate the power quality degradation and functioning in bidirectional mode.

During the charging process the consumed current is sinusoidal with unitary power factor, and it is possible to control the voltage and the current in the batteries through an appropriate control algorithm, in order to preserve the batteries lifespan. Beyond the charging process, it is also possible to discharge a small part of the stored energy in the batteries back to the electrical power grid, which in the near future, taking into account the Vehicle-toGrid (V2G) concept in Smart Grids, can be an interesting solution during short periods of times when occur peaks of energy demand in the electrical system, as well as to work as a distributed Energy Storage System (ESS). The operation of the smart batteries charger is shown through simulation and experimental results.

Also in this paper was briefly described and shown the key concepts related with the Smart Grids in terms of Systems and Functional Areas, Power Electronics Systems, and Electric Mobility.

\section{ACKNOWLEDGEMENTS}

This work is financed by FEDER Funds, through the Operational Programme for Competitiveness Factors - COMPETE, and by National Funds through FCT - Foundation for Science and Technology of Portugal, under the project PTDC/EEA-EEL/104569/2008 and the project MITPT/EDAM-SMS/0030/2008.

\section{REFERENCES}

Bollen, J., Zhong, J., Zavoda, F., Meyer, J., McEachern, A., \& Lopez, F. (2010). Power Quality aspects of Smart Grids. In ICREPQ'10, International Conference on Renewable Energies and Power Quality, Granada, Spain.

Bradley, T. H., \& Frank, A. A. (2009). Design, demonstrations and sustainability impact assessments for plug-in hybrid electric vehicles. In ELSEVIER, Renewable and Sustainable Energy Reviews 13.

Carvalho, A., \& Cooper, J. (2011). The Advanced Smart Grid - Edge Power Driving Sustainability. In Artech House, ISBN 13: 978-1-60807-127-2.

Clement, K., Haesen, E., \& Driesen, J. (2009). Coordinated charging of multiple plug-in hybrid electric vehicles in residential distribution grids. In IEEE/PES Power Systems Conference and Exposition.

ETPSG. (2010). Strategic Deployment Document for European's Electricity Networks of the Future. European Technology Platform Smart Grid.

Ferreira, J. C., Silva, A. R., Monteiro, V., \& Afonso, J. L. (2011). Collaborative Broker for Distributed Energy Resources. In International Symposium on Computational Intelligence for Engineering Systems (ISCIES), Coimbra, Portugal.

Han, Sekyung, Han, S., \& Sezaki, K. (2010). Development of an Optimal Vehicle-to-Grid Aggregator for Frequency Regulation. In IEEE Transactions on Smart Grid.

Kisacikoglu, M. C., Ozpineci, B., \& Tolbert, L. M. (2010). Examination of a PHEV bidirectional charger system for $\mathrm{V} 2 \mathrm{G}$ reactive power compensation. In TwentyFifth Annual IEEE Applied Power Electronics Conference and Exposition (APEC).

MAGICC. (2011). Mid-Atlantic Grid Interactive Cars Con sortium. Retrieved from http://www.magicconsortium. org/research_partners.html

Wei, H., \& Batarseh, I. (1998). Comparison of basic converter topologies for power factor correction. In Proceedings IEEE Southeastcon '98. ”Engineering for a New Era".

Wiedemuth, P., Bontemps, S., \& Minibock, J. (2007). 35 $\mathrm{kW}$ Active Rectifier with Integrated Power Modules. In Proceedings of the Conference for Power Electronics, Intelligent Motion, Power Quality (PCIM'07). 